\title{
EVALUATION OF SERUM MAGNESIUM LEVEL IN PREECLAMPSIA
}

\author{
HL Roy$^{1}$, S Nargis ${ }^{2}$, SH Mahmud ${ }^{3}$, NWB Jahan ${ }^{4}$, MS Hossain ${ }^{5}$, M Majumder ${ }^{5}$, H Begum ${ }^{6}$ \\ ${ }^{1}$ Dept of Biochemistry, Khulna City Medical College, Khulna; ${ }^{2}$ Dept of Biochemistry, Ad-din Sakina \\ Medical College, Jessore; ${ }^{3}$ Dept of Pharmacology and Therapeutics, Army Medical College Comilla, \\ Comilla Cantonment; ${ }^{4}$ Dept of Obst. \& Gayne., Sir Salimullah Medical College \& Mitford Hospital, \\ Dhaka; ${ }^{5}$ Dept of Biochemistry, Sylhet MAG Osmani Medical College, Sylhet; ${ }^{6}$ Dept of Biochemistry, \\ Sylhet MAG Osmani Medical College, Sylhet
}

\begin{abstract}
Preeclampsia is the most common medical complication of pregnancy associated with increased maternal and infant mortality and morbidity. Reduced serum magnesium level is found to be associated with elevated blood pressure in preeclampsia. The purpose of this cross-sectional study is to evaluate the serum magnesium level in preeclamptic women. For this study 50 preeclamptic patients, with age range 20 to 40 years having gestational age range from 20 to 40 weeks and 50 age and gestational age matched normotensive pregnant women having no proteinuria were enrolled. Serum magnesium was measured by colorimetric method. The mean $( \pm S D)$ age and mean $( \pm S D)$ gestational age of preeclampsia was not significantly different from those of normotensive pregnant women $(p=0.203$ and $p=0.251$ respectively). The mean $( \pm S D)$ body mass index of the preeclamptic patients was significantly higher compared to that of normotensive pregnant women $(p<0.001)$. The mean $( \pm \mathrm{SD})$ serum magnesium level was $3.37 \pm 2.05 \mathrm{mg} / \mathrm{dl}$ in preeclamptic group and $2.87 \pm 1.38 \mathrm{mg} / \mathrm{dl}$ in normal pregnant women; the level did not differ significantly between the subject of preeclampsia and normal pregnant women $(p=0.153)$. Findings of this study suggest that serum magnesium has no association with preeclampsia.
\end{abstract}

Key Words: Preeclampsia, Magnesium

\section{Introduction}

Preeclampsia is an idiopathic multisystem disorder specific to human pregnancy ${ }^{1}$. It is defined as the onset of hypertension and the presence of proteinuria during pregnancy, usually occurring after the 20th week of gestation in a previously normotensive woman and resolving completely by the sixth week after delivery of fetus ${ }^{2}$.

Preeclampsia is a transient but potentially dangerous complication of pregnancy. Generally, the incidence of preeclampsia is in the range of $4-8 \%$ of all pregnancies ${ }^{3}$. The incidence of preeclampsia has fallen in developed countries due to improved antenatal

Bangladesh J Med Biochem 2017; 10(1): 10-15 care, but it's incidence is still high in the developing countries 4 , and preeclampsia accounts for about $20-80 \%$ of the maternal mortality in developing countries 5 . Preeclampsia and eclampsia cause about $16 \%$ of maternal death in Bangladesh 4 .

Despite of preeclampsia's prevalence and severity, the pathophysiology of this multisystem disorder is still poorly understood and it's etiology has not yet been fully elucidated. Environmental and nutritional factors may play a role in the development of preeclampsia 6 . The epidemiology of preeclampsia, being more common in poor women, long ago suggested that nutrients might be involved in the disorder ${ }^{7}$. It is 
assumed that deficiency of several essential micronutrients may be a predisposing factor in the development of preeclampsia because nutrients can modulate oxidative stress by increasing or decreasing free radicals or antioxidant and providing substrates for formation of free radicals ${ }^{4}$. Nutritional deficiencies are commonly found in pregnant women and it is well established that the pregnant women from developing countries usually consume diets that are low in minerals and vitamins 8 .

Magnesium is the second most abundant intracellular cation and the fourth most abundant cation in the body9. Magnesium is an essential cofactor for many enzyme systems. It also plays an important role in neurochemical transmission and peripheral vasodilation ${ }^{10}$. Some studies have reported that reduction in serum level of magnesium during pregnancy might be possible contributors in etiology and pathogenesis of preeclampsia and supplementation of this element to diet may be of value to prevent preeclampsia11.

Several studies observed significantly low serum magnesium level in preeclamptic women as compared to normal pregnant $(\mathrm{p}<0.05)^{12-16}$. But many studies reported that serum levels of magnesium did not differ significantly between preeclamptic and non preeclamptic groups ${ }^{17,18}$. Serum magnesium level was significantly lower in preeclamptic women compared to normal pregnant women in a study in Dhaka, Bangladesh ${ }^{21}$. This is not enough to reach valid conclusion. So, this study was conducted to estimate the serum magnesium level in preeclampsia and normal pregnancy and to find out association between serum magnesium and preeclampsia.

\section{Materials and Methods}

This cross-sectional study was carried out in the Department of Biochemistry, Sylhet MAG Osmani Medical College in collaboration with the
Department of Obstetrics and Gynaecology, Sylhet MAG Osmani Medical College Hospital during the period from January 2016 to December 2016. Fifty preeclamptic patients, with age range of 20 to 40 years having gestational age range from 20 to 40 weeks (group-A) and 50 age- and gestational agematched normotensive pregnant women having no proteinuria (group-B were enrolled in the study. Informed written consent was taken from each of the patient or legal guardian and an approval of study protocol was obtained from the ethical committee of Sylhet MAG Osmani Medical College prior to the commencement of the study. All primi pregnant women having essential hypertension, systemic or endocrine disorders, malabsorption syndrome, and patients on magnesium supplementation were excluded. Detailed history about present pregnancy regarding preeclampsia and other known disorders were taken. Gestational age was determined based on last menstrual date and confirmed by ultrasound examination. Data were collected from the selected subjects on variables of interest using a semistructured questionnaire by interview, observation, clinical examination, investigation and from the history. Blood pressure was measured in supine position or sitting position. Urine was tested for gross proteinuria (heat coagulation test). The preeclamptic patients were diagnosed by the presence of persistent hypertension (more than $140 / 90 \mathrm{~mm}$ of $\mathrm{Hg}$ ), gross proteinuria (tested by heat coagulation test of urine), and pathological edema. Maternal weight was recorded in kilograms with the subject standing on the weight machine without shoes and minimum clothing. Maternal height was recorded with the subject barefooted, feet together, back against the upright bar of the height scale, head upright in Frankfort horizontal plane-look straight ahead. The height measuring equipment consists of a vertical bar with a horizontal bar of wood which was brought down on examinee's head. Body mass index (BMI) was calculated by the formula $(\mathrm{BMI}=$ Weight in kilogram/Height in meter ${ }^{2}$ ). 
Five $\mathrm{ml}$ of venous blood was collected from antecubital vein under aseptic precaution in a metal-free sterile tube without any anticoagulant. Test tube was coded for identification of sample. The sample was kept at room temperature for about 20-25 minutes to allow it to clot and was sent to the Department of Biochemistry, Sylhet MAG Osmani Medical College, Sylhet where serum magnesium was measured by colorimetric method.

Data were analyzed with the help of Statistical Package for Social Science (SPSS) Version21. Quantitative data was expressed as mean $( \pm S D)$ (standard deviation) and unpaired Student's ' $t$ ' test was done to see the level of significance. Qualitative data were expressed as frequency and percentage. The p-value of $<0.05$ was considered statistically significant.

\section{Results}

The mean $( \pm S D)$ age was $26.70 \pm 5.59$ years in preeclamptic Group-A and $25.32 \pm 5.17$ years in normotensive pregnant women Group-B; the difference was not statistically significant $(p=0.203)$ as shown in Figure-1. The mean $( \pm \mathrm{SD})$ gestational age was $32.14 \pm 3.19$ weeks in preeclampsia Group-A and $32.84 \pm 2.86$ weeks in normotensive pregnant women Group$\mathrm{B}$; the difference was not statistically significant $(\mathrm{p}=0.251)$ as depicted in Figure-1. The mean $( \pm S D)$ body mass index was $25.98 \pm 2.58$ in preeclamptics and $22.49 \pm 2.72$ in normotensive pregnant women. The mean $( \pm \mathrm{SD})$ body mass index in preeclamptics was significantly higher compared to normotensive pregnant women $(p<0.001)$ shown in Figure-1.

The mean $( \pm \mathrm{SD})$ serum magnesium level was $3.37 \pm 2.05 \mathrm{mg} / \mathrm{dl}$ in preeclamptic (Group-A) and $2.8 \pm 1.38 \mathrm{mg} / \mathrm{dl}$ in normal pregnant women (Group-B). The mean $( \pm \mathrm{SD})$ serum magnesium level did not differ significantly between groups $(p=0.153)$ shown in Figure-2.

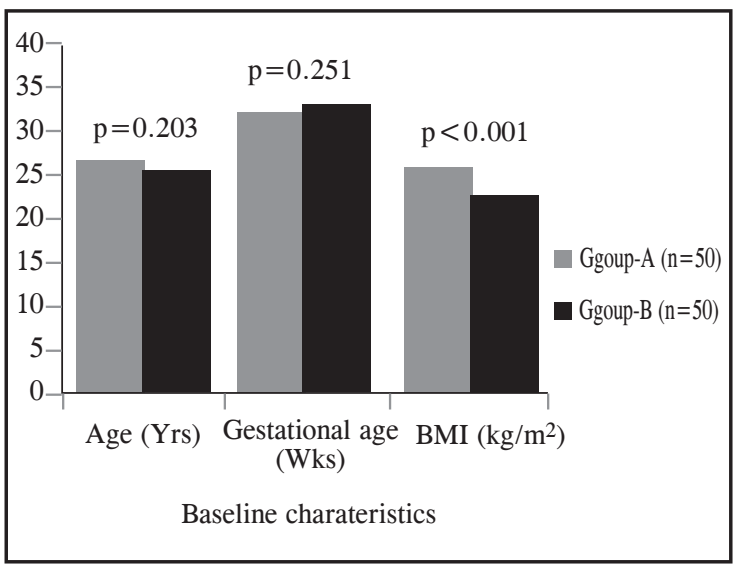

Figure-1: Baseline characteristics of the study subjects of both groups

Unpaired Student's ' $t$ ' test was done to reach a level of significance. $p<0.05$ was the level of significance.

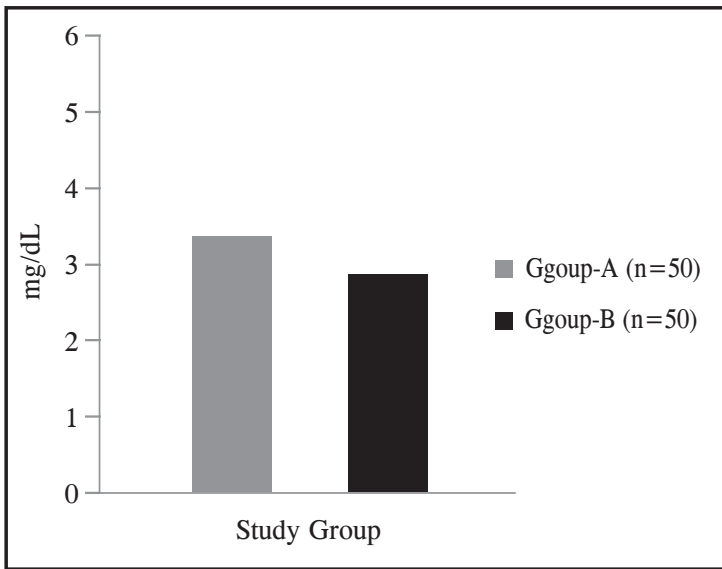

Figure-2: Serum magnesium level in study groups

Unpaired Student' ' $t$ ' test was used to reach a level of significance. $p<0.05$ was the level of significance.

\section{Discussion}

Serum concentrations of various macro- and micro-minerals are altered during pregnancy with changes in the mother's physiology and the requirements of growing fetus. Changes in serum level of Magnesium (Mg) during pregnancy were estimated. In addition, it has 
Evaluation of Serum Magnesium Level in Preeclampsia been reported that reduction in serum level of $\mathrm{Mg}$ during pregnancy might be a possible contributor in etiology of preeclampsia (PE), and supplementation of these minerals to diet may be of value to prevent PE18.

In this study the mean $( \pm S D)$ age in preeclamptics and normal pregnant women did not differ significantly $(p=0.203)$. The mean $( \pm S D)$ age was $26.70 \pm 5.59$ years in preeclamptic group which agree with the findings of many other studies 17,19 . In this study the mean $( \pm S D)$ gestational age was $32.14 \pm 3.19$ weeks in the subjects with preeclampsia and $32.84 \pm 2.86$ weeks in normal pregnant women. There was no significant difference of mean gestational age between two groups $(p=0.251)$. This result was similar to the study of Akhtar et al.19 who found gestational age to be $31.53 \pm 3.90$ weeks in preeclampsia group and $32.3 \pm 3.53$ weeks in normal pregnancy group; the difference was not significant $(\mathrm{p}=0.321)$. Ephraim et al. 20 also reported that the gestational age of their study subject was $30.72 \pm 2.84$ weeks in preeclampsia and $31.92 \pm 4.69$ in normal pregnancy; the difference was not significant $(\mathrm{p}=0.2518)$.

This study showed that the mean $( \pm \mathrm{SD}) \mathrm{BMI}$ was $22.97 \pm 2.62$ in the subjects with preeclampsia and $22.49 \pm 2.7$ in the normal pregnant women. The BMI of the subjects did not differ significantly between groups $(p=0.362)$. This result was consistent with the study of Lambe et al. ${ }^{14}$ who found mean BMI to be $22.75 \pm 1.99$ in preeclampsia and $23.01 \pm 2.0$ in normal pregnant women. The BMI of the subjects did not differ significantly between two groups $(p=0.4854)$. Several other studies did not show significant difference of body mass index between the two groups $(p>0.05)^{8,17}$. But Akhtar et al. 19 found that the mean BMI of the subjects with preeclampsia was 25.30 (SEM 0.36 ) and in normal pregnant women was 23.48 (SEM 0.28) which was not statistically significant $(\mathrm{p}<0.001)$.
In the current study the mean $( \pm S D)$ serum magnesium level was $3.3 \pm 2.05 \mathrm{mg} / \mathrm{dl}$ in preeclampsia and $2.87 \pm 1.38 \mathrm{mg} / \mathrm{dl}$ in normal pregnant women. The mean serum magnesium level did not differ significantly between the subjects of preeclampsia and normal pregnant women $(p=0.153)$. This result was supported by different studies6,12,20 who also found no significant difference between the plasma magnesium of the patients and controls. But several other studies ${ }^{8,14,21-23}$ showed that there was significantly lower serum magnesium in preeclampsia than that of normal pregnancy. Recently Dickinson et al. ${ }^{24}$ in a meta analysis of 12 randomized trials with follow-up ranging from 8 to 26 weeks showed that causal association between magnesium supplementation and BP reduction was weak. A dose-response pattern was found in another meta-analysis with twenty studies who reported that magnesium intake only resulted in a small overall reduction in $\mathrm{BP}^{25}$.

The limitations of the present study are that small sample size and samples were taken from a single tertiary care Government Hospital where people of all socioeconomic status may not attend. Literature review revealed conflicting findings about serum magnesium in preeclamptic women. Like many other studies our study also showed that serum magnesium has no association in occurrence of preeclampsia. However further multicentre study involving large sample size to solve this conflicting issue is recommeded.

\section{References}

1. Mittal S, Shaikh MKS, Thakur R, Jain D. Comparison of serum calcium and magnesium levels between preeclamptic and normotensive healthy pregnant women. Int J Reprod Contracept Obs Gynecol 2014; 3: 959-62.

2. Al-Rubaye FG. Trace Elements Homeostasis in Preeclampsia. Iraqi J Med Sci 2009; 2: 116-23. 
3. Manjareeka M, Nanda S. Serum electrolyte levels in pre-eclamptic women: a comparative study. Int J Pharma Bio Sci 2012; 3: 572-8.

4. Sarwar MS, Ahmed S, Ullah MS, Kabir H, Rahman GKMM, Hasnat A. Comparative Study of Serum Zinc, Copper, Manganese and Iron in Pre-eclamptic Pregnant Women. Biol Trace Elem Res 2013; 154: 14-20.

5. Baruah K, Choudhury B, Borgohain MK, Choudhury NH. A comparative study of the serum calcium level in normal pregnant and preeclamptic women attending Gauhati Medical College and Hospital. Int J Biomed Adv Res 2015; 6: 776-9.

6. Kanagal DV, Rajesh A, Rao K, Devi UH, Shetty H, Kumari S. Levels of Serum Calcium and Magnesium in Preeclamptic and Normal Pregnancy: A Study from Coastal India. J Clin Diag Res 2014; 8: 1-4.

7. Gupta S, Jain NP, Avasthi K, Wander GS. Plasma and Erythrocyte Zinc in Preeclampsia and its Correlation with Fetal Outcome. J Assoc Physic Ind 2014; 62: 12-16.

8. Akinloye O, Oyewale OJ, Oguntibeju OO. Evaluation of trace elements in pregnant women with preeclampsia. Afr J Biotechnol 2010; 9: 5196-202.

9. Swaminathan R. Magnesium Metabolism and its Disorders. Clin Biochem Rev 2003; 24: 47

10. Kosch M, Hauseberg M, Louwen F, Barenbrock M, Rahn KH, Kisters K. Membrane, intracellular and plasma magnesium and calcium concentration in preeclampsia. $\mathbf{J}$ Hum Hypertens 2000; 14: 333-6.

11. Yazbeck C, Thiebaugeorges O, Moreau T, Goua V, Debotte G, Sahuquillo J. Maternal blood lead levels and the risk of pregnancy-induced hypertension: the EDEN cohort study. Environ Health Perspect 2009; 117: 1526-1530.
12. Punthumapol C, Kittichotpanich B. Serum calcium, magnesium and uric acid in preeclampsia and normal pregnancy. J Med Assoc Thai 2008; 91: 968-73.

13. Chaurasia PP, Jadav PA, Jasani JH. Changes in serum calcium and serum magnesium level in preeclamptic vs normal pregnancy. Int $\mathbf{J}$ Biomed Adv Res 2012; 03: 511-3.

14. Lambe S, Mahajan B, Muddeshwar M. Comparative Study of Serum Calcium, Magnesium and Zinc Levels in Preeclampsia and Normal Pregnancy. Int $\mathbf{J}$ Recent Trends Sci Technol 2014; 9: 422-6.

15. Abdellah A, Abdrabo AKA. Assessment of serum calcium, magnesium, copper and zinc levels in Sudanese pregnant women with preeclampsia. Global Adv Res J 2014; 3(2): 33-6.

16. Saila BS, Kala C, Saradamba K. Serum Calcium and Magnesium Levels in Women Presenting with Pre-Eclampsia: a CaseControl Study in North Coastal Andhra Pradesh. IOSR J Dent Med Sci (IOSRJDMS) 2014; 14: 44-6.

17. Golmohammad lou S, Amirabi A, Yazdian M, Pashapour N. Evaluation of Serum Calcium, Magnesium, Copper and Zinc Levels in Women with Preeclampsia. Iran J Med Sci 2008; 33: 231-4.

18. Vafaei H, Dalili M, Hashemi SA. Serum concentration of calcium, magnesium and zinc in normotensive versus preeclampsia pregnant women: A descriptive study in women of Kerman province of Iran. Iran J Reprod Med 2015; 13: 23-6. 
19. Vahidrodsari F, Ayaty S, Tourabizadeh A, Ayat-Allahi H, Esmaeli H, Shahabian M. Serum calcium, magnesium in preeclamsia and normal pregnancies: A comparative study. J Reprod Infert 2008; 9: 256-62.

20. Adewolu OF. Serum sodium, potassium, calcium and magnesium in women with pregnancy-induced hypertension and preeclampsia in Oredo local government, Benin Metropolis: A pilot study. Afr J Med Health Sci 2013; 12: 1-5.

21. Nahar K, Yasmin H, Shamsuddin L. Serum Magnesium in Preeclampsia and Eclampsia. Bangladesh J Obstet Gynaecol 2010; 25(1): 15-19

22. Farzin L, Sajadi F. Comparison of serum trace element levels in patients with or without preeclampsia. J Res Med Sci 2012; 17: 938-941.
23. Singh A, Verma AK, Hassan G, Prakash V, Sharma P, Kulshrestha S. Serum magnesium levels in patients with preeclampsia and eclampsia with different regimens of magnesium sulphate. Global J Med Public Health 2013; 2: 1-9.

24. Dickinson HO, Nicolson DJ, Campbell F, Cook JV, Beyer FR, Ford GA. Magnesium supplementation for the management of essential hypertension in adults. Cochrane Database Syst Rev 2006. 19: CD004640.

25. Jee SH, Miller ER. Guallar E. Singh VK, Appel LJ, Klag MJ. The effect of magnesium supplementation on blood pressure: a meta analysis of randomized clinical trials. Am J Hypertens 2002; 15: 691-696. 